\title{
Cassava postharvest physiological deterioration: a complex phenomenon involving calcium signaling, reactive oxygen species and programmed cell death
}

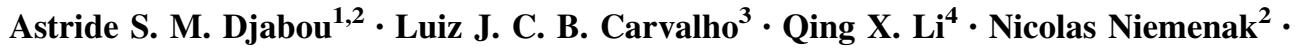 \\ Songbi Chen ${ }^{1}$
}

Received: 15 August 2015/Revised: 30 January 2017/Accepted: 11 February 2017/Published online: 3 March 2017

(C) The Author(s) 2017. This article is published with open access at Springerlink.com

\begin{abstract}
Postharvest physiological deterioration (PPD) of cassava (Manihot esculenta) storage roots is a complex physiological and biochemical process which involve many regulatory networks linked with specific proteins modulation and signaling transduction pathways. However, it is poorly understood regarding biological regulation, and the interactions among protein groups and signals to determine PPD syndrome in cassava storage roots. This review sheds some light on the possible molecular mechanisms involved in reactive oxygen species (ROS), calcium signaling transduction, and programmed cell death (PCD) in cassava PPD syndrome. A model for predicting crosstalk among calcium signaling, ROS and PCD is suggested to fine-tune PPD syndrome. This would clues to cassava molecular breeding to alleviate the PPD effects on the shelf-life.
\end{abstract}

Keywords Manihot esculenta . Postharvest physiological deterioration $\cdot$ Calcium signaling $\cdot$ ROS $\cdot$ Programmed cell death $\cdot$ Crosstalk

Communicated by A. K. Kononowicz.

Songbi Chen

songbichen@hotmail.com

1 Tropical Crops Genetic Resources Institute, Chinese Academy of Tropical Agricultural Sciences/Key Laboratory of Ministry of Agriculture for Germplasm Resources Conservation and Utilization of Cassava, Hainan, China

2 Laboratory of Plant Physiology, Department of Biological Science, Higher Teachers' Training College, University of Yaounde I, Yaounde, Cameroon

3 Genetic Resources and Biotechnology, Embrapa, Brazil

4 Department of Molecular Biosciences and Bioengineering, University of Hawaii at Manoa, Honolulu, USA

\section{Introduction}

Cassava (Manihot esculenta Crantz) is a vegetative propagated shrub belonging to the Euphorbiaceae family. In the tropics, where it is a major staple food crop, cassava is the $4^{\text {th }}$ most important source of calories (Bradbury 1988). Resilience to drought and disease and tolerance to low-soil fertility enable it to grow well under a wide range of climatic conditions, where few crops could survive without costly external inputs. Despite these agronomic advantages, cassava storage roots (CSR) are far more perishable after harvest compared to other storage root and tuber crops, such as sweet potato, true yam, corn and potato. Therefore, cassava is range as a sensitive species of postharvest deterioration (An et al. 2012). The rapid deterioration of CSR significantly shortens its shelf-life for fresh consumption and impacts transportation and potential for income generation (Westby 2002; Iyer et al. 2010). This phenomenon is known as postharvest physiological deterioration (PPD). Estimated losses reach up to 8, 10, and $29 \%$ in Asia, Latin America and Caribbean, and Africa, respectively (FAO 2000). Root damage during harvest alters the equilibrium of natural physiological process of the exposed cells and subsequently their oxidative burst. Since PPD is a complex biological phenomenon, it is expected to involve early events (Buschmann et al. 2000a) as the observed dark strips of vessels due to oxidation of cell components (Apostol et al. 1989; Reilly et al. 2004) as tissue wounding reaction (Beeching et al. 2002). Later on, deterioration of cell allows microorganism growth.

This review summarized the current knowledge on oxidative events, participation of calcium signaling events and programmed cell death in association with PPD syndrome. An exploratory model was proposed for prediction of crosstalk among calcium $\left(\mathrm{Ca}^{2+}\right)$ signaling, reactive 
oxygen species (ROS) production and scavenge, and apoptosis. The model could be used to predict PPD syndrome.

\section{Morphological and histological changes of storage root due to exposure of root cells to ambient air}

Cassava storage roots are far more perishable than other staple food crops. Subsistence and commercial utilization of cassava are affected by its short shelf-life due to a rapid postharvest physiological deterioration process (Westby et al. 2002). The duration of cassava shelf-life depends on the cultivars, harvest practices and handing, and storage conditions. However, PPD commonly occurs within $72 \mathrm{~h}$ after harvest and renders the root unpalatable (Buschmann et al. 2000b; Iyer et al. 2010). Formation and growth of cassava storage root are resulted from the swelling of primary roots due to the secondary growth which forms three tissue layers. The first, second and third tissue layers are composed of phellogen and phelloderm, cambium and phloem, and secondary vessels and store parenchyma cells, respectively (De Souza et al. 2006). PPD syndrome is first observed in the third tissue layer (the edible part of CSR) by visualization of dark colors changes in a cross section of a storage root (Fig. 1). This is associated with formation of the so-called dark strip of xylem vessels. Microscopic tissue sectioning observation (Fig. 2) shows that the dark strip is associated with the formation of tylose occlusions inside the secondary vessels and may be the oxidized candidate cell structure since the xylem is a dead cell. PPD considered as primary deterioration, is initiated by mechanical damage which occurs during harvesting. This is known as PPD. The visible signs are black blue to black discoloration or vascular streaking which begins at the broken or cut surfaces and subsequently spreads to the adjacent storage parenchyma and the stored starch undergoes structural changes. This primary deterioration is characterized by physiological and biochemical changes, and does not involve microorganisms (Noon and Booth 1977). Therefore, it is a biological active process and distinct from the secondary deterioration caused by microbial infection leading to softening of the root tissue (Sánchez et al. 2013; García et al. 2013). The later events of PPD syndrome involve the formation of callus from the exposed cells as healing process proceeds in addition to cell death. Difference in susceptibility to PPD amount cassava varieties has been reported (Aristizábal and Sánchez 2007; Morante et al. 2010a, b; Salcedo et al. 2010). In addition, an inversely correlation between light yellow parenchyma color of roots associated to high amount of carotenoid content and delaying of PPD was reported by Chavez et al. (2007). In fact, it is suggested that cassava wound repair can occur if the root remains attached to the plant (Plumbey and Rickard 1991; Reilly et al. 2004). Then, the problem takes place once the root is detached. Although the wound response is present, the healing process and the subsequent down-regulation of the signals are insufficient or too low (Salcedo and Siritunga 2011). It is thought that at some point during evolution cassava roots lost their efficiency in wound repair (Reilly et al. 2004). In addition, extent of PPD damage and speed of symptom development in roots was also associated to the genotypic as well as the environmental conditions increasing the complexity of the phenomenon (Reilly et al. 2004).

In the level of histology, the increase of oxidative stress caused by wounding may induce a metachromatic reaction observed by staining with toluidine blue indicating the presence of acidic polysaccharides in the cell wall and around starch granules (Uarrota et al. 2014). Acidic polysaccharides may act as reducing PPD stress. In addition, the degradation of starch granules during PPD evolution was clearly observed after staining with periodic
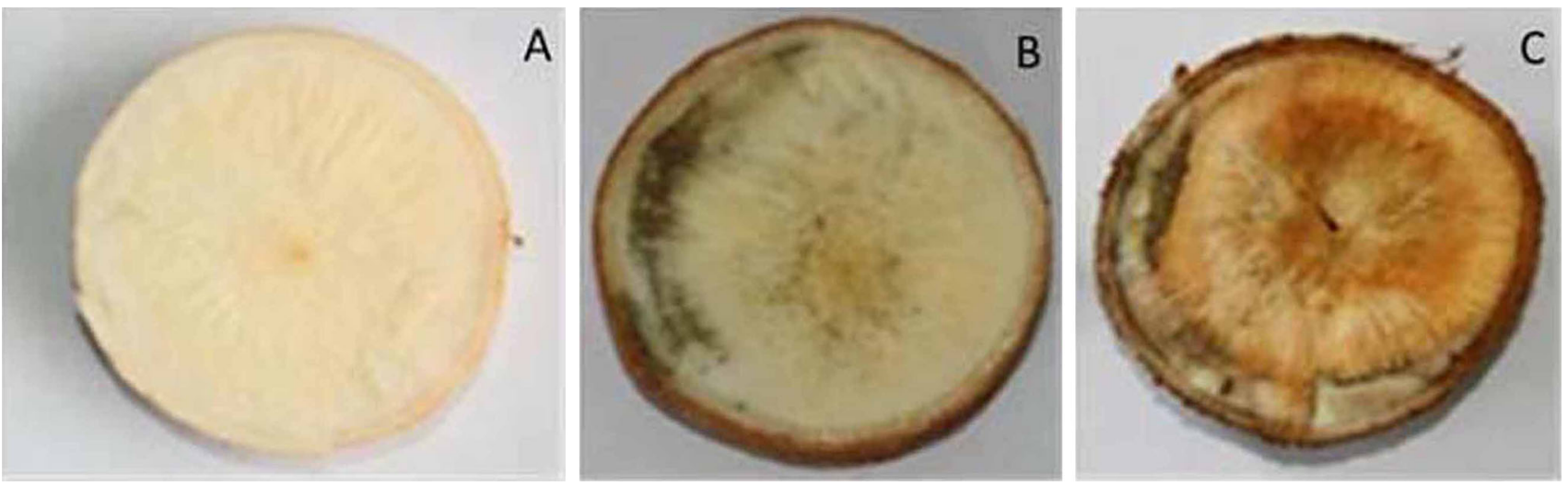

Fig. 1 Cross sections of cassava freshly harvested storage roots exposed to air for zero (a), three (b), and ten days (c). Blue-black/ brown discolorations recognized as a visual sign of PPD are clearly observed at 3 days. The discolorations continued until ten days following by the softening of the roots given place to development of microorganisms (secondary deterioration) 

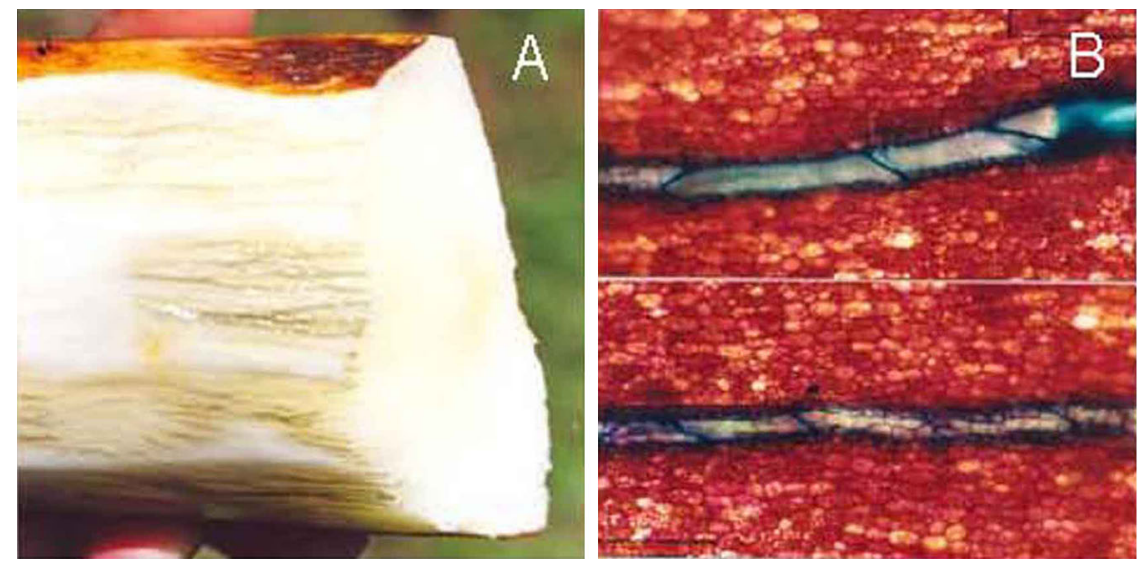

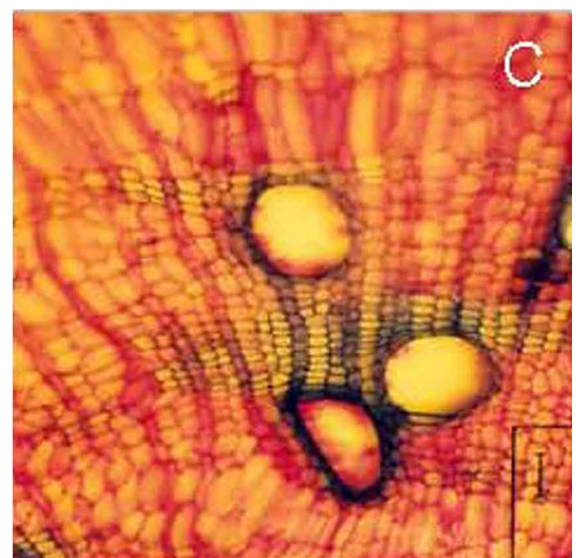

Fig. 2 Microscopic observation of cassava storage roots undergoing PPD. a Dark strip formation in vessels of tissue system III resulting from oxidative process. b Close longitudinal cutting showing detailed

acid Schiff (Uarrota and Maraschin 2015). Previously, Canto et al. (2013) did not observe alterations in the primary xylem after storage during PPD, suggesting that PPD process happens mainly in the peripheric region of the root without affecting the vascular cambium (primary xylem).

\section{Biochemical features of PPD syndrome}

Several studies have been performed to investigate the biochemical feature and molecular events related to PPD syndrome (Reilly et al. 2004, 2007; Owiti et al. 2011). Changes in response to cell damages after CSR harvest included accumulation of fluorescent compounds and secondary metabolites (Buschmann et al. 2000a, b), decrease of starch content in the profit of sugar (Sánchez et al. 2013); the main soluble sugars found by high performance light chromatography were raffinose, sucrose, fructose, and glucose (Uarrota et al. 2014); increase in cell respiration and enzymatic activities including regulation of ROS synthetase (Xu et al. 2013; Zidenga et al. 2012) as well as phenylammonia-lyase. PPD has been found to be correlated with the content of $\beta$-carotene since Morante et al. (2010a, b) observed a less susceptibility to PPD for the genotypes with high level of $\beta$-carotene compared to those with less level of $\beta$-carotene. PPD development was also associated to change in gene expression where many genes get altered during the process (Huang et al. 2001; Cortés et al. 2002). Zidenga et al. (2012) suggested that mechanical damage that occurs during harvesting is initiated cyanogenesis by bringing linamarin and linamarase in contact and subsequently the release of cyanide. The cyanide $(\mathrm{HCN})$ released inhibits mitochondrial respiration by inhibiting complex IV in the mitochondrial electron transfer chain. Inhibition of complex IV causes a burst of vessels fully observable of tylose occlusion. c Close-up of tylose occlusion formation inside secondary vessels was observed

ROS production at complexes I and III. It is this oxidative burst that causes PPD. Recent studies about metabolome analyses showed increases in carotenoids, flavonoids, anthocyanins, phen-olics, reactive scavenging species, and enzymes (superoxide dismutase family, hydrogen peroxide, and catalase) under PPD (Uarrota et al. 2014). In the same study, a positive correlation was observed between PPD and antocyanins and flavonoids while a negative correlation was observed with phenolics compounds and carotenoids. Several proteins were up- or down-regulated during the process (Owiti et al. 2011). Plant responds to various stresses such as pathogen attacks, harsh growing conditions, wounding by inducing the expression of a large number of genes that encode diverse proteins. The response of plant tissues to wounding has been studied for a very long time and more recently it has been demonstrated that several genes are wound-inducible. The proteomic approach is a very powerful tool to study the proteins patterns that result from differential gene expression as well as from post-translational modifications (Gray and Heath 2005; Lee et al. 2007; Timperio et al. 2008). Proteome profile of CSR at harvest and during PPD onset revealed 300 proteins showing significant abundance regulation during PPD (Vanderschuren et al. 2014). The identified proteins were mostly associated with oxidative stress, phenylpropanoid biosynthesis (including scopoletin), the glutathione cycle, fatty acid-oxidation, folate transformation, and the sulfate reduction II pathway in which glutathione peroxidase was identified as a possible candidate for reducing PPD. All the information clearly showed that PPD is an active and complex phenomenon involving the possible interaction/crosstalk between the pathways. 


\section{The role of ROS in plants}

Plants and other living organisms in the oxidizing environment constantly produce ROS from chloroplasts, mitochondria, peroxisomes and other subcellular organelles because of biological metabolic processes such as photosynthesis and respiration. Overproduction of ROS is triggered by a pathogen attack and stress exerted by environmental conditions. ROS or active oxygen species (AOS) or reactive oxygen intermediates (ROI) include the superoxide radical $\left(\mathrm{O}_{2}^{-}\right)$, hydroxyl radical $(\mathrm{OH} \cdot)$, hydroperoxyl radical $\left(\mathrm{HO}_{2}^{-}\right)$, hydrogen peroxide $\left(\mathrm{H}_{2} \mathrm{O}_{2}\right)$, alkoxy radical (RO-), peroxy radical (ROO-) and singlet oxygen $\left({ }^{1} \mathrm{O}_{2}\right)$ (Vellosillo et al. 2010). Plants have either enzymatic or non-enzymatic defense systems to scavenge ROS toxicity and protect against oxidative damage (Vranova and Inze 2002). The enzymatic scavenging system includes superoxide dismutase (SOD), ascorbate peroxidase (APX), catalase (CAT), glutathione peroxidase and glutathione reductase while the non-enzymatic scavenging system includes ascorbic acid (AsA), glutathione and proline. In response to environmental stresses, plants produce increased levels of ROS and SOD which provides the first line of defense is, thus, important in plant stress tolerance (Apel and Hirt 2004). The increase of glutathione reductase activity confers stress tolerance and has the ability to alter the redox state of important components of the electron transport chain (Foyer and Noctor 2011). The organism equilibrium is determined by the ROS homeostasis, including ROS producing in combination with its scavenging. Contact with invading microbe as well as wounding in many plants elevates plant plasma membrane-bound NADPH activity, leading to the rapid accumulation of ROS including hydrogen peroxide $\left(\mathrm{H}_{2} \mathrm{O}_{2}\right)$, which diffuses into cells and activates defenses (Apel and Hirt 2004). Increasing evidence indicates that ROS has a dual role as cytotoxic damage, and as a signaling molecule involved in the regulation of response during pathogen attack or various physiological processes (Foyer and Noctor 2005; Mittler et al. 2004; Corpas et al. 2015). The accumulation of ROS in the site of infection during hypersensitive response may contribute to limit the spread of the pathogens or induce signals for establishment of further defense (Mur et al. 2008). Feedback, or feed-forward interaction between ROS and many hormones such as ethylene, jasmonic acid, abscisic acid, gibberellic acid and salicylic acid in response to biotic and abiotic stresses has also been presented (Mittler et al. 2004; Mur et al. 2008). Since ROS is ideally suited to act as signaling molecules because of its small size and ability to diffuse over short distances (Mittler et al. 2004; Pei et al. 2000; Overmyer et al. 2000), it is not surprisingly that numerous researchers paid close attention to the oxidative burst in damage cassava storage roots.

\section{Features of ROS associated to PPD syndrome}

Cassava storage root is inevitable predisposed to cell damage due to mechanical injury caused by harvest. Therefore, constitutive defense mechanisms are activated upon harvest as in intact plant subjected to abiotic stress. The response of cell damage produces ROS including superoxide anion and hydrogen peroxide with both local and systemic action (Apel and Hirt 2004). In the case of CSR, studies have been focused on the ROS production and their scavenging induced by cell damage during PPD syndrome (Xu et al. 2013; Zidenga et al. 2012). A burst of superoxide anion and the increased activities of ROS scavenging enzymes such as superoxide dismutase and catalase were observed after oxidative burst caused by harvest damage (Iyer et al. 2010; Reilly et al. 2007). The shortage of scavenge of the overproduced ROS results in accelerate PPD. Previously, Zidenga et al. (2012) suggested that the cyanide produce immediately when cassava is mechanically damaged may trigger the oxidative burst responsible of PPD onset. In fact cassava produces potentially toxic levels of cyanogenic glucosides which break down to release cyanide following cellular disruption and release cyanogens from the vacuole (Siritunga and Sayre 2003; Siritunga et al. 2004). Therefore, increasing the production of ROS scavenges is presented as a key regulator of PPD. The induction of the overexpression of mitochondrial alternative oxidase (AOX) in transgenic cassava was followed by extending of the shelf-life of storage root (SR) for two weeks (Zidenga et al. 2012). Parallel experiments showed that the co-overexpression of $\mathrm{Me} / \mathrm{Cu} / \mathrm{Zn}-\mathrm{SOD}$ and MeCAT1 induced in transgenic cassava could also enhance scavenging ROS in CSR after tissue damage (Xu et al. 2013). In addition, the regulation of the activity of glutathione-associated enzymes, including glutathione reductases, glutaredoxins, and glutathione S-transferases have been reported as potential modulator for the onset of PPD (Vanderschuren et al. 2014). Recently, increase in APX, GPX, AsA, and CAT subsequently detoxify the hydrogen peroxide was recently reported in cassava roots during PPD (Uarrota and Maraschin 2015). Taken together these observations strongly support the implication of ROS during PPD process and present many pathways which may trigger their production.

\section{Features of calcium signaling associated to PPD syndrome}

Plant cells could trigger their elaborate defense systems while perceiving signal messenger coming from their environment, and eventually produce proper physiological responses. In plants, calcium ion $\left(\mathrm{Ca}^{2+}\right)$ is a ubiquitous second messenger molecule coupling with physiological 
response to external and developmental signals (Reddy and Reddy 2004). It plays a key role in the integrity of the cell wall and the membrane systems and acts as an intracellular regulator in many aspects of plant growth and development including stress responses (White and Breadly 2003). Changes in cytosolic free $\mathrm{Ca}^{2+}$ concentration were observed during transduction of abiotic stimuli including high light, low and high temperature, hyperosmotic and oxidative stresses and also in the biotic stimuli including fungal elicitors and nodulation factors (Rudd and FranklinTong 2001). These $\mathrm{Ca}^{2+}$ signatures are recognized by several types of $\mathrm{Ca}^{2+}$-sensor proteins. $\mathrm{Ca}^{2+}$-binding sensory proteins include calmodulins ( $\mathrm{CaMs})$, calmodulin-like proteins, calcineurin B-like proteins (CBL), and $\mathrm{Ca}^{2+}$-dependent protein kinases (CDPKs) (Sanders et al. 2002; Snedden and Fromm 2003).

There is an ample evidence to show the involvement of $\mathrm{Ca}^{2+}$ signaling in abiotic stress responses. Intracellular changes of $\mathrm{Ca}^{2+}$ levels were reported as the first response to diverse abiotic signals and biotic stresses (Beneloujaephajri et al. 2013; Ranty et al. 2006). Numerous data supported that $\mathrm{Ca}^{2+}$ and its sensor proteins, CaM, CDPKs and CBLs and downstream elements played an important role in plant adaptation to abiotic stress. Several studies indicated $\mathrm{Ca}^{2+}-\mathrm{CaM}$ complex triggered the activation of target proteins to produce cellular physiological responses (Bouché et al. 2005; Nookaraju et al. 2011). An example was found in tobacco stressed by wounding, in which three $\mathrm{CaM}$ isoforms at different $\mathrm{Ca}^{2+}$ concentrations activate the target enzymes NO synthase and NAD kinase (Karita et al. 2004). Similar effect of $\mathrm{Ca}^{2+}$ on NO or NAD kinase during PPD cannot be ruled out.

In the case of cell injuries such as the one occurring in PPD syndrome of CSR, a significant up-regulation of CaM observed at the early events of PPD (Owiti et al. 2011) can be associated with a rapid increase in $\mathrm{Ca}^{2+}$ which resulted in the oxidative burst as observed in Arabidopsis thaliana (Kaplan et al. 2006). This phenomenon was similar to the expression of heat shock proteins under heat stress attributed to the accumulation of CaM in plants (Liu et al. 2003; Zhang et al. 2009). $\mathrm{Ca}^{2+}$ seems to be involved in signaling transduction to trigger the activation of programed cell death (PCD) (Zhang et al. 2009; Hoeberichts and Woltering 2002; Levine et al. 1996). It was suggested that CDPKs, in response to elevated cytosolic $\mathrm{Ca}^{2+}$ levels, could induce NADPH oxidase activity which is one of the key points of an oxidative burst and PCD process (Hoeberichts and Woltering 2002). In roots of Arabidopsis thaliana, mechanical stimulation triggered the rapid and transient increase of cytoplasmic $\mathrm{Ca}^{2+}$ concentration; this mechanical stimulation likewise elicits apoplastic ROS production with the same kinetics (Monshausen et al. 2009).

\section{Programmed cell death features in plants}

Programmed cell death (PCD) is an active and genetically controlled process aimed at eliminating redundant or harmful cells from healthy tissues during the life cycle of the multicellular organism. It is a highly regulated cellular suicide process and essential for growth and survival in eukaryotes. The biochemical and morphological hallmarks of PCD recorded to be common to plants and animals are compaction and shrinkage of the cytoplasm and nucleus, DNA and nuclear fragmentation into large (50-300 kb) and subsequently small nucleosomal fragment (200 bp, DNA laddering) and calcium influx (De Jong et al. 2000; Wang et al. 1996). PCD was reported in many biological processes in plants including embryogenesis, flower petal senescence and vegetative development such as xylogenesis, and parenchyma formation. Various stress conditions such as cold, nutrient deprivation, salts or D-mannose stresses, pathogen or pathogen toxin (Wang et al. 1996) have been found to induced DNA laddering and subsequently death in plants. PCD is also a process involving new protein synthesis and distinct from necrosis, cell death caused by extrinsic factors, and independent of specific genetic control and cellular activities (Van Breusegem and Dat 2006).

The core component of the apoptotic machinery found in animals is a proteolytic cascade involving a family of cysteine proteases named caspases, which specifically cleave at aspartic acid residues of their substrates (Shi 2002; Zhang et al. 2009). This cleavage may be involved in the detachment of the dying cell making it easy to ingest (Shi 2002). Even if no homologs of animal's caspases have been identified in plants, accumulated evidence in the recent years suggests caspases-like activity playing a pivotal role in plant PCD (He et al. 2008; Woltering et al. 2002). The expression of caspase-3-like has been detected from barley embryonic suspension cells and TMV-infected tobacco leaves (Lam and Zhang 2012). Parallel experiments were performed to show the cleavage of Poly (ADP Ribose) polymerase, a specific substrate of caspase-3 during the apoptotic process in animal by extracting from fungus-infected cowpea. Comparing to the animal apoptotic pathway, this degradation was dependent on the release of cytochrome $\mathrm{c}$ into the cytosol and could be inhibited by specifics caspase 3 inhibitors. Using the synthetic fluorogenic caspase-1 substrate (Ac-DEVD-AMC), caspase-like activity was also detected during UV- or heat shock-induced apoptosis of plant cells, and this could be inhibited by caspase- 3 inhibitors but not by caspase-unrelated protease (Vacca et al. 2006). All of these experiments evidenced that the functional caspase-like proteolytic activity was detected and its functional involvement in plant cells undergoing PCD. 
Recently, the metacaspase, a homolog of caspase, implicated in plant PCD was also detected (Koonin and Aravind 2002; Uren et al. 2000). Even if it was unable to cleave caspase substrates, it was found to be involved in PCD in Arabidopsis and yeast (He et al. 2008; Madeo et al. 2002). The level of cell death was increased in transgenic plant by overexpressing some Arabidopsis metacaspases (AtMC4, AtMC5) upon treatment with ROS inducing agents and the loss of those genes resulted in a decrease or delay of cell death (Lam and Zhang 2012). PCD following oxidative burst has been demonstrated in many plants (Woltering et al. 2002; Vacca et al. 2006; Danon et al. 2000). Several calcium-binding proteins were induced in response to the stresses. CDPKs, in response to elevated cytosolic $\mathrm{Ca}^{2+}$ level, can induce NADPH oxidase, which catalyzes the production of ROS such as superoxides (Sagi and Fluhr 2006). Even if the oxidative burst induced by wound in cassava storage root after harvest has been studied, the linkages between oxidative burst and PCD are poorly understood. In fact, high concentrations of ROS are highly harmful to organisms, and when the symptoms persist, irreversible damage may occur to the cells, resulting in loss of physiological capacity and eventual cell death.

Regarding cassava storage root PPD, PCD process was marked by the down-regulation of cysteine protease which may enhance protease activity leading to PCD as well as the down regulation of many peptides of the phospholipase $\mathrm{D} \alpha$-group of the enzymes during the early and late PPD times points were also presented (Owiti et al. 2011). However, further studies need to be carried out to describe how this pathway works in a PPD process. Biochemical detection of caspase-3-like activity and its inhibitors in plant PCD can be useful to elucidate the mechanism of PPD. Apart from this further functional characterization, understanding of the mechanism on which this pathway interacts with other pathways such as $\mathrm{Ca}^{2+}$ and ROS like mentioned in others plants during stress can increase the knowledge about the PPD process in cassava.

\section{Crosstalk among $\mathrm{Ca}^{2+}$ signaling, ROS and PCD integration network in cassava to fine-tune PPD syndrome}

In cassava, the events that trigger the production of ROS relevant to PPD under abiotic and biotic stresses are poorly understood. Information is rising about the implication of $\mathrm{Ca}^{2+}$ in the release of ROS in wound-induced resistance in plant (Beneloujaephajri et al. 2013; Sagi and Fluhr 2006; Bargmann and Munnik 2006). In response to wound induced by Botrytis cinerea, it was found that non-wounded leaves of Arabidopsis thaliana treated with $\mathrm{Ca}^{2+}$ inhibitors were more susceptible to pathogen, suggesting the importance of $\mathrm{Ca}^{2+}$ in the induction of basic resistance
(Beneloujaephajri et al. 2013). Interestingly, a co-localization of the changes in $\mathrm{Ca}^{2+}$ and a burst of ROS were observed after pathogenic or environmental stresses were exerted (Monshausen et al. 2009; Ranf et al. 2011). The transient changes in $\mathrm{Ca}^{2+}$ concentration were detected for a few seconds after wounding, followed by the increase of ROS concentration in A. thaliana leaves after wounding (Beneloujaephajri et al. 2013). Indeed, in plants a positive feedback mechanism involving NADPH oxidase, ROS and $\mathrm{Ca}^{2+}$ was (Sagi and Fluhr 2006). Various $\mathrm{Ca}^{2+}$ binding proteins such as CDPKs in response to elevated cytosolic $\mathrm{Ca}^{2+}$ levels could induce NADPH oxidase activity, leading to the increase of ROS under stresses (Sagi and Fluhr 2006), and potentially trigger other downstream responses such as apoptosis. CDPK6, a $\mathrm{Ca}^{2+}$ related protein of $A$. thaliana, was reported to be involved in the regulation of ROS (Boudsocq and Sheen 2010). An ortholog of this protein found in potato was involved in the phosphorylation of the membrane-bound NADPH oxido-reductase RBOH-D to stimulate its activity for ROS production in response to pathogen attacks (Kobayashi et al. 2007). However, ROS production from the initial $\mathrm{Ca}^{2+}$-dependent activation can subsequently trigger a larger $\mathrm{Ca}^{2+}$ influx (Pei et al. 2000; Kadota et al. 2004). Thus, it is possible that $\mathrm{Ca}^{2+}$ cytosolic elevation is crucial for ROS accumulation, which in turn contributes to $\mathrm{Ca}^{2+}$ signaling in positive feedback loop (Sagi and Fluhr 2006; Bargmann and Munnik 2006). The crosstalk between the second messengers $\mathrm{Ca}^{2+}$ and $\mathrm{ROS}$ is now recognized in the modulation of the activity of specific proteins that act at the nuclear level to control the expression of determinate defense genes. In plants, $\mathrm{Ca}^{2+}$ fluxes were also recognized as an important signaling mediator of the activation of PCD and NADPH oxidase complexes may be stimulated by caspase (-like) activity (Hoeberichts and Woltering 2002). They may trigger the reduction of oxygen to $\mathrm{O}_{2}{ }^{-}$followed by dismutation of $\mathrm{O}_{2}{ }^{-}$to $\mathrm{H}_{2} \mathrm{O}_{2}$. Subsequently, caspase inhibitors can act to prevent cell death and the preceding accumulation of ROS. Increasing evidence indicated that an interaction may exist between elevated cytosolic $\mathrm{Ca}^{2+}$, accumulation of ROS and subsequent cell damage. Zidenga et al. (2012) showed that the accumulation of ROS during PPD can be the consequence of cyanide released during cyanogenesis and did not observe a substantial reduction of ROS production with diphenyl iodonium chloride an inhibitor of membrane NADPH oxidase. The up-regulation of $\mathrm{CaM}$ one of the most important calcium sensors proteins coupled to the increase of cysteine protease during early PPD suggest the implication of others pathways on PPD process recognize as an active process. Growth regulators can interact in coordination under various stress conditions in order to control the downstream stress response or with others pathways to fine-tune the defenses (Verma et al. 
Membrane

Nucleus

Mitochondria

Protein

Functional Class

Small Molecule

Cell Process

Treatment

$\mathbf{R}>$ Regulation

Ms $>$ MolSynthesis

$\rightarrow$ ChemicalReaction

Mt $>$ MolTransport

$B>$ DirectRegulation

$\mathbf{E} \rightarrow$ Expression

\section{$\rightarrow$ Binding}

Fig. 3 Putative crosstalk among $\mathrm{Ca}^{2+}$, ROS and apoptosis in cassava storage roots during PPD. The network was generated with Pathway Studio software default. Regulation is marked as an arrow with $R$, MolSynthesis as an arrow with Ms, Chemical Reaction as an arrow

2016). The response of plants imposed by abiotic stress such as wound in cassava roots could be mainly controlled by growth regulators even if it remains poorly understood. Taking all information together PPD induced in CSR seems to reflect an integrative crosstalk between signaling molecules, including $\mathrm{Ca}^{2+}-\mathrm{CaM} / \mathrm{CDPK}$, ROS, hormones such as jasmonic acid, salicylic acid, ethylene, gibberellin acid, cysteine protease and still unknown members of PCD pathway.

Based on the data described above, we would propose a mechanism of PPD in cassava. All impact factors associated with PPD were used to generate a biological interaction network using Pathway Studio. This network includes cell process, functional class, protein, small molecule and osmotic stress treatment. The relationship among chemical reaction, expression, regulation, and binding was established (Fig. 3) responding to defense response and oxidative stresses caused from wound damage and microbial infection. Mechanical damage causes by wound induces oxidative burst and stimulates $\mathrm{Ca}^{2+}$ influx. This flux is sensed by $\mathrm{Ca}^{2+}$ binding proteins such as $\mathrm{CaM}$ which has several $\mathrm{Ca}^{2+}$-dependent in vitro activities. It is involved in regulating various cellular and biochemical processes, such as PPD. $\mathrm{Ca}^{2+}$ signaling was essential for activating the $\mathrm{NO}$ and ROS production induced by mechanical damage. Therefore, $\mathrm{Ca}^{2+}-\mathrm{CaM}$ complex is a key center to regulate ROS homeostasis. Other key points are with $C$, MolTransport as an arrow with Mt, Direct Regulation as an arrow with D, Expression as an arrow with $E$ and Binding as an arrow without any marks

ROS and apoptosis. ROS are responsible for mediating cellular defense responses in cassava. The production of ROS, mediated through NADPH oxidase, increases under stress conditions such as wound damage, causing oxidative burst and impairment of normal metabolism. ROS are also key elements in cassava PCD which is essential for microbial infection. In the model, a negative control on cell death-dependent ROS accumulation, promoted by SA and ethylene is limited by jasmonic acid (Fig. 3). In addition, CAT and SOD can interfere with hormones to scavenge the flux of ROS produced restore the equilibrium and PPD can be delayed. In contrary, the increasing production of ROS can trigger both a second peak of $\mathrm{Ca}^{2+}{ }_{\text {cyt }}$ which interfere with mitochondrion and the production of MAPK. MAPK can act with heat shock proteins and others cell death pathway inducing cell wall degradation and subsequently PPD and PCD. All together, we consider PPD in cassava as a complex process in which the crosstalk among $\mathrm{Ca}^{2+}$ signaling, ROS and PCD is integrated to fine-tune.

\section{Conclusion}

Cassava storage roots is an essential part of the daily diet for millions people and income generation. However, its potential as food and industrial crop is still limited by PPD. 
The study of PPD mechanism response is important in increasing our molecular knowledge and for their potential in developing an effective approach to control PPD losses. The recent data revealed the implication of $\mathrm{Ca}^{2+}-\mathrm{CaM}$, ROS and PCD pathways in response to PPD. The crosstalk between these pathways during PPD process is proposed in this review. However, more functional studies are needed to better understand when, where and how the proteins involved in these pathways talk or interact to fine-tune the PPD response. Progress in proteomic, cell image technology and molecular genetic analysis will be helpful to drive future research and provide a worthwhile approach to control PPD in cassava storage roots.

Author contribution statement SC made the major contributions to this study in the conception, design, drafting part of manuscript, and final revision. ASMD contributed to part of the conception and design, and drafting manuscript. LJCBC worked at Fig. 2 and revision of manuscript. QXL contributed to part of conception, and critical revision of manuscript. NN worked at part of design and critical revision of manuscript. All authors read and approved the final manuscript.

Acknowledgements This work was supported by NSFC-CGIAR Project (31361140366), National Science and Technology Infrastructure Program (2015BAD15B01), the Initial Fund of High-level Creative Talents in Hainan Province, and the National Scientific and Technological Programs in Rural Fields (2012AA101204-2). The funders had no role in study design, data collection and analysis, decision to publish, or preparation of the manuscript.

Open Access This article is distributed under the terms of the Creative Commons Attribution 4.0 International License (http://crea tivecommons.org/licenses/by/4.0/), which permits unrestricted use, distribution, and reproduction in any medium, provided you give appropriate credit to the original author(s) and the source, provide a link to the Creative Commons license, and indicate if changes were made.

\section{References}

An D, Yang J, Zhang P (2012) Transcriptome profiling of low temperature treated cassava apical shoots showed dynamic responses of tropical plant to cold stress. BMC Genom 13:64

Apel K, Hirt H (2004) Reactive oxygen species: metabolism, oxidative stress, and signal transduction. Annu Rev Plant Biol 55:373-399

Apostol I, Heinstein PF, Low PS (1989) Rapid stimulation of an oxidative burst during elicidation of cultured plant cells: role in defense and signal transduction. Plant Physiol 90:106-116

Aristizábal J, Sánchez T (2007) Technical guide for the production and analysis of cassava starch. Bulletin of Agriculture Services of the FAO. (pp. 134). Rome. Italy

Bargmann BOR, Munnik T (2006) The role of phospholipase D in plant stress responses. Curr Opin Plant Biol 9:515-522

Beeching JR, Gómez-Vásquez R, Li H, Han Y, Rodriguez MX, Buschmann H, Taylor N, Fauquet C, Tohme J (2002) Postharvest physiological deterioration of cassava. In: Nakatani, M,
Komaki K (Eds.), 12th Symposium of the International Society for Tropical Root Crops, Potential of root crops for food and industrial resources pp 60-66

Beneloujaephajri Costa E, L’Haridon A, Métraux F, Binda JPM (2013) Production of reactive oxygen species and wound-induced resistance in Arabidopsis thaliana against Botrytis cinera are preceded and depend on a burst of calcium. BMC Plant Biol 13:160

Bouché N, Yellin A, Snedden WA, Fromm H (2005) Plant-specific calmodulin-binding proteins. Annu Rev Plant Biol 56:35-466

Boudsocq M, Sheen J (2010) Stress signaling II: calcium sensing and signaling. In: Pareek, A. Sopory SK, Bohnert HT, Govindjee (eds) Abiotic stress adaptation in plants: physiological, molecular and genomic foundation, pp 75-90

Bradbury JH (1988) The chemical composition of tropical root crops. Asian Food J 4:3-13

Buschmann H, Rodriguez MX, Tohme J, Beeching JR (2000a) a Accumulation of hydroxycoumarins during post-harvest deterioration of tuberous roots of Cassava (Manihot esculenta Crantz). Ann Bot 86:1153-1160

Buschmann H, Reilly K, Rodriguez MX, Tohme J, Beeching JR (2000b) b Hydrogen peroxide and flavan-3-ols in storage roots of cassava (Manihot esculenta Crantz) during postharvest deterioration. J Agric Food Chem 48:5522-5529

Canto AR, da Júnior NSF, Beleia A (2013) Chemical and histological changes in stored cassava roots of cultivars Catarina Amarela and Catarina Branca. Acta agronómica 62(2):106-114

Chavez AL, Sanchez T, Ceballos H, Rodriguez-Amaya DB, Nestel P, Thome J, Ishitani M (2007) Retention of carotenoids in cassava roots submitted to different processing methods. J Sci Food Agric 87:388-393

Corpas FJ, Gupta DK, Palma JM (2015) Reactive oxygen species and oxidative damage in plants under Stress. In: Gupta DK, Palma JM, Corpas FJ (eds) Radionuclides in the Environment: Influence of Chemical Speciation and Plant Uptake on Radionuclide Migration. Springer, Germany

Cortés DF, Reilly K, Okogbenin E, Beeching JR, Iglesias C, Tohme J (2002) Mapping wound response genes involved in postharvest physiological deterioration (PPD) of cassava (Manihot esculenta Crantz). Euphytica 128:47-53

Danon A, Delorme V, Maithae N, Gallois P (2000) Programmed cell death: a common way to die. Plant Physiol Biochem 38:647-655

De Jong AJ, Hoeberichts FA, Yakimova ET, Maximova E, Woltering EJ (2000) Chemical induced apoptotic cell death in tomato cells: involvement of caspase-like proteases. Planta 211:656-662

De Souza CRB, Carvalho LJCB, De Almeida ERP, Gander ES (2006) A cDNA sequence coding for a glutamic acid-rich protein is differentially expressed in cassava storage roots. Protein Peptide Lett 13:653-657

FAO (2000) The World cassava economy, facts, trends and outlook FAO. Rome Italy pp 46

Foyer CH, Noctor G (2005) Redox homeostasis and antioxidant signaling: a metabolic interface between stress perception and physiological responses. Plant Cell 17:1866-1875

Foyer CH, Noctor G (2011) Ascorbate and glutathione: the heart of the redox hub. Plant Physiol 155(1):2-18

García JA, Sánchez T, Ceballos H, Alonso L (2013) Non-destructive sampling procedure for biochemical or gene expression studies on post-harvest physiological deterioration of cassava roots. Postharvest Biol Technol 86:529-535

Gray GR, Heath D (2005) A global reorganization of the metabolome in Arabidopsis during cold acclimation is revealed by metabolic fingerprinting. Physiol Plant 124(2):236-248

He R, Drury GE, Rotari VI, Gordon A, Willer M et al (2008) Metacaspase- 8 modulates programmed cell death induced by ultraviolet light and $\mathrm{H}_{2} \mathrm{O}_{2}$ in Arabidopsis. J Biol Chem 283:774-778 
Hoeberichts FA, Woltering EJ (2002) Multiple mediators of plant programmed cell death: interplay of conserved cell death mechanisms and plant-specific regulators. BioEssays 25:47-57

Huang J, Bachem C, Jacobsen E, Visser R (2001) Molecular analysis of differentially expressed genes during postharvest deterioration in cassava (Manihot esculenta Crantz) tuberous roots. Euphytica 120:85-93

Iyer S, Mattinson DS, Fellman JK (2010) Study of the early events leading to cassava root postharvest deterioration. Trop Plant Biol 3:151-165

Kadota Y, Goh T, Tomatsu H, Tamauchi R, Higashi K, Muto S, Kuchitsu K (2004) Cryptogein-induced initial events in tobacco BY-2 cells: pharmacological characterization of molecular relationship among cytosolic $\mathrm{Ca}^{2+}$ transients, anion efflux and production of reactive oxygen species. Plant Cell Physiol 45:160-170

Kaplan B, Davydov O, Knight H, Galon Y, Knight MR, Fluhr R, Fromm H (2006) Rapid transcriptome changes induced by cytosolic $\mathrm{Ca}^{2+}$ transients reveal ABRE-related sequences as $\mathrm{Ca}^{2+}$-responsive cis elements in Arabidopsis. Plant Cell 18:2733-2748

Karita E, Yamakaw H, Mitsuhar I, Kuchitsuki Ohashi Y (2004) Three types of tobacco calmodulins characteristically activate plant NAD kinase at different $\mathrm{Ca}^{2+}$ concentration and pHs. Plant Cell Physiol 45:1371-1379

Kobayashi A, Akiko T, Yoko K, Yutaka M, Nobuharu F, Atsushi H, Hideyuki T (2007) A gene essential for hydrotropism in roots. Proc Natl Acad Sci 104:4724-4729

Koonin EV, Aravind L (2002) Origin and evolution of eukaryotic apoptosis: the bacterial connection. Cell Death Diff 9:394-404

Lam E, Zhang Y (2012) regulating the reapers: activating metacaspases for programmed cell death. Trends Plant Sci 17:487-494

Lee D-G, Ahsan N, Lee SH, Kang KY, Bahk JD, Lee IJ, Lee BH (2007) A proteomic approach in analyzing heat-responsive proteins in rice leaves. Proteomics 7(18):3369-3383

Levine A, Pennel RI, Alvarez ME, Palmer R, Lamb C (1996) Calcium-mediated apoptosis in plant hypersensitive disease resistance response. Curr Biol 6:427-437

Liu HT, Li B, Shang ZL, Li XZ, Mu RL, Sun DY, Zhou RG (2003) Calmodulin is involved in heat shock signal transduction in wheat. Plant Physiol 132:1186-1195

Madeo F, Herker D, Maldener C, Wissing S, Lachtelt S, Herlan M, Fehr M, Lauber K, Sigrist SJ, Wesselborg S, Fröhlich KU (2002) A caspase-related protease regulates apoptosis in yeast. Mol Cell 9:1-2

Mittler R, Vanderauwera S, Gollery M, Van Breusegem F (2004) Reactive oxygen gene network of plants. Trends Plant Sci 9:490-498

Monshausen GB, Bibikova TN, Weisenseel MH, Gilroy S (2009) $\mathrm{Ca}^{2+}$ regulates reactive oxygen species production and $\mathrm{pH}$ during mechanosensing in Arabidopsis roots. Plant Cell 21:2341-2356

Morante N, Sánchez T, Ceballos H, Calle F, Pérez J, Egesi CC, Cuambe CE, Escobar AF, Ortiz D, Chávez AL, Fregene M (2010a) Tolerance to postharvest physiological deterioration in cassava roots. Crop Sci 50:1333-1338

Morante N, Sánchez T, Ceballos H, Calle F, Pérez J, Egesi CC, Cuambe CE, Escobar AF, Ortiz D, Chávez AL, Fregene M (2010b) Tolerance to postharvest physiological deterioration in cassava roots. Crop Sci 50:1333-1338

Mur LAJ, Kenton P, Amanda J, Lloyd Ougham H, Elena P (2008) The hypersensitive response; the centenary is upon us but how much do we know? J Exp Bot 59:501-520

Nookaraju A, Pandey SK, Upadhyaya CP, Heung JJ, Hyun SK, Chul Chun S, Doo HK, Park SW (2011) Role of $\mathrm{Ca}^{2+}$ mediated signaling in potato tuberization: An overview. Bot Stud 53:177-189
Noon RA, Booth RH (1977) Nature of post-harvest deterioration of cassava roots. Trans B Mycol Soc 69:287-290

Overmyer K, Tuominen H, Kettunen R, Betz C, Langebartels C, Sandermann H, Kangasjarvi J (2000) Ozone-sensitive arabidopsis rcd1 mutant reveals opposite roles for ethylene and jasmonate signaling pathways in regulating superoxide-dependent cell death. Plant Cell 12:1849-1862

Owiti J, Grossmann J, Gehrig P, Dessimoz C, Laloi C, Hansen MB, Gruissem W, Vandreshuren H (2011) iTRAQ-based analysis of changes in the cassava root proteome reveals pathways associated with postharvest physiological deterioration. Plant J 67:145-156

Pei ZM, Murata Y, Benning G, Thomine S, Klusener B, Allen GJ, Grill E, Schroeder (2000) Calcium channels activated by hydrogen peroxide mediate abscisic acid signalling in guard cells. Nature 406:731-773

Plumbey RA, Rickard (1991) Postharvest deterioration in cassava. Trop. Sci. 31:295-303

Ranf S, Lennart E, Pascal P, Lee J, Dierk S (2011) Interplay between calcium signalling and early signalling elements during defence responses to microbe- or damage-associated molecular patterns. Plant J 68:100-113

Ranty B, Aldon D, Galaud JP (2006) Plant calmodulins and calmodulin-related proteins. Plant Signal Behav 3:96-104

Reddy VS, Reddy AS (2004) Proteomics of calcium-signaling components in plants. Phytochemistry 65:1745-1776

Reilly K, Gomez-vasquez R, Buschmann H, Tohme J, Beeching JR (2004) Oxidative stress responses during cassava postharvest physiological deterioration. Plant Mol Biol 56:625-641

Reilly K, Bernal D, Cortes DF, Gomez-vasquez R, Tohme J, Beeching JR (2007) Towards identifying the full set of genes expressed during cassava postharvest deterioration. Plant Mol Biol 64:187-203

Rudd JJ, Franklin-Tong VE (2001) Unravelling response specificity in $\mathrm{Ca}^{2+}$ signaling pathways in plant cells. New Phytol 151:7-33

Sagi M, Fluhr R (2006) Production of reactive oxygen species by plant NADPH oxidases. Plant Physiol 141:336-340

Salcedo A, Siritunga D (2011) Insights into the physiological and the molecular basis of postharvest deterioration in cassava (Manihot esculenta) roots. Am J Exp Agri 1(4):414-431

Salcedo A, Del Valle A, Sanchez B, Ocasio V, Ortiz A, Marquez P, Siritunga D (2010) Comparative evaluation of physiological post-harvest root deterioration of 25 cassava (Manihot esculenta) accessions: visual vs. hydroxycoumarins fluorescent accumulation analysis. Afr J Agric Res 5:3138-3144

Sánchez T, Dufour D, Moreno JL, Pizarro M, Aragón IJ, Domínguez M, Ceballos H (2013) Changes in extended shelf life of cassava roots during storage in ambient conditions. Postharvest Biol Technol 86:520-528

Sanders D, Pelloux J, Brownnlee C, Harper JF (2002) Calcium at the crossroads of signaling. Plant Cell 14:401-417

Shi YG (2002) Mechanism of caspase activation and inhibition during apoptosis. Mol Cell 9:459-470

Siritunga D, Sayre R (2003) Generation of cyanogen-free transgenic cassava. Planta 217:367-373

Siritunga D, Arias-Garzon D, White W, Sayre RT (2004) Overexpression of hydroxynitrile lyase in transgenic cassava roots accelerates cyanogenesis and food detoxification. Plant Biotech $\mathbf{J}$ 2:37-43

Snedden WA, Fromm A (2003) Calmodulin as a versatile calcium signal transducer in plants. New Phytol 15:135-166

Timperio AM, Egidi MG, Zolla L (2008) Proteomics applied on plant abiotic stresses: role of heat shock proteins (HSP). J Proteom 71(4):391-411

Uarrota VG, Maraschin M (2015) Metabolomic, enzymatic, and histochemical analyzes of cassava roots during postharvest physiological deterioration. BMC Res Notes 8:648 
Uarrota Moresco R, Coelho B, da Nunes EC, Peruch LAM, Enilto de Oliveira N, Rocha M, Maraschin M (2014) Metabolomics combined with chemometric tools (PCA, HLA, PLS-DA and SVM) for screening cassava (Manihot esculenta, Crantz) roots during postharvest physiological deterioration. Food Chem 161:67-78

Uren AG, O'Rourke K, Aravind L, Pisabarro MT, Eugene SS, Koonin V, Dixit VM (2000) Identification of paracaspases and metacaspases: two ancient families of caspase-like proteins, one of which plays a key role in MALT lymphoma. Mol Cell 4:961-967

Vacca RA, Valenti D, Bobba A, Merafina RS, Passarella S, Marra E (2006) Cytochrome $c$ is released in a reactive oxygen speciesdependent manner and is degraded via caspase-like proteases in tobacco Bright-Yellow 2 cells en route to heat shock-induced cell death. Plant Physiol 141:208-219

Van Breusegem F, Dat J (2006) Reactive oxygen species in plant cell death. Plant Physiol 141:384-390

Vanderschuren H, Nyaboga E, Poon JS, Baerenfaller K, Grossmann J, Hirsch-Hoffmann M, Kirchgessner N, Nanni P, Gruissem W (2014) Large-Scale Proteomics of the cassava storage root and identification of a target gene to reduce postharvest deterioration. Plant Cell 26:1913-1924

Vellosillo T, Vicente J, Kulasekaran S, Hamberg M, Castresana C (2010) Emerging complexity in reactive oxygen species production and signaling during the response of plants to pathogens. Plant Physiol 154:444-448

Verma V, Ravindran P, Kumar PP (2016) Plant hormone-mediated regulation of stress response. BMC Plant Physiology 16:86
Vranova E, Inze DFVB (2002) Signal transduction during oxidative stress. J Exp Bot 53:1227-1236

Wang H, Li J, Bostock RM, Gilchrist DG (1996) The apoptosis: a functional paradigm for programmed plant cell death induced by a host-selective phytotoxin and invoked during development. Plant Cell 8:375-391

Westby A (2002) Cassava utilization, storage and small-scale processing. In: Hillocks RJ, Thresh JM, Bellotti AC (eds) Cassava biology, production and utilization. CABI Publishing Oxfordshire, UK, pp 480

White PJ, Breadly MR (2003) Calcium in plants. Ann Bot (land) 92:487-511

Woltering EJ, van der Bent A, Hoeberichts FA (2002) Do plant caspases exist? Plant Physiol 130:1764-1769

Xu J, Xiao GD, Yang J, Beeching JR, Zhang P (2013) Enhanced reactive oxygen species scavenging by overproduction of superoxide dsimutase and catalase delays postharvest physiological deterioration of cassava storage rot. Plant Physiol $161: 1517-1528$

Zhang W, Zhou RG, Gao YJ, Zheng SZ, Xu P, Zhang SQ, Sun DY (2009) Molecular and genetic evidence for the key role of AtCaM3 in heatshock signal transduction in Arabidopsis. Plant Physiol 149:1773-1784

Zidenga T, Leyva-Guerrero E, Moon H, Siritunga D, Sayre R (2012) Extending cassava root shelf life via reduction of reactive oxygen species production. Plant Physiol 159:1396-1407 